\title{
SOBRE A IMPORTÂNCIA DE ENSINAR EXPRESSÕES IDIOMÁTICAS
}

\author{
Susana Termignoni \\ Maria José Bocorny Finatto*
}

RESUMO: Este artigo está inserido no âmbito de duas vertentes da Fraseologia Contrastiva: a Fraseografia Bilíngue e a Fraseodidática, tendo como foco uma subcategoria das unidades fraseológicas - as expressões idiomáticas. Neste artigo, não abordaremos a Fraseografia, mas a importância mundial crescente da Fraseodidática, apresentando as razões pelas quais acreditamos firmemente que as unidades fraseológicas devam fazer parte do programa de aprendizagem de uma língua estrangeira. Para isso, foi desenhado um protótipo de dicionário on-line semibilíngue para a compreensão de expressões idiomáticas italiano-português, voltado para aprendizes brasileiros de língua italiana de nível intermediárioavançado.

PALAVRAS-CHAVE: expressão idiomática; italiano-português; fraseodidática; ensino.

RIASSUNTO: Questo articolo si inserisce nell'ambito di due filoni della Fraseologia Contrastiva: la Fraseografia Bilingue e la Fraseodidattica, ed è incentrato su una sottocategoria delle unità fraseologiche - le espressioni idiomatiche. In questo articolo non tratteremo di Fraseografia, ma della crescente importanza internazionale della Fraseodidattica, presentando le ragioni per cui crediamo fortemente che le unità fraseologiche debbano far parte del programma di apprendimento di una lingua straniera. A questo scopo, è stato progettato un

\footnotetext{
* Universidade Federal do Rio Grande do Sul, Porto Alegre (Brasil) - stermignoni@ yahoo.com.br/mariafinatto@gmail.com
}

DOI: http://dx.doi.org/10.11606/issn.2238-8281.v0i35p112-124 
modello di dizionario on-line semibilingue di espressioni idiomatiche italianoportoghese brasiliano, rivolto alla comprensione e destinato a apprendenti brasiliani di lingua italiana di livello intermedio-avanzato.

PAROLE-CHIAVE: espressione idiomatica; italiano-portoghese; fraseodidattica; insegnamento.

ABSTRACT: This article falls under two strands of contrastive phraseology: bilingual phraseography and phraseodidactics, focusing on a subset of phraseological units: idiomatic expressions. In this article, we will not discuss Phraseography, but rather the increasing international importance of Phraseodidactics, presenting also the reasons why we strongly believe that phraseological units should be part of a foreign language learning program. In order to do this, we designed a prototype of a semi-bilingual Italian-Brazilian Portuguese online dictionary of idiomatic expressions for intermediate-advanced Brazilian learners of Italian, in order to help in comprehension.

KEYWORDS: idioms; Italian-Portuguese; Phraseodidactics; teaching. 


\section{Introdução ${ }^{1}$}

Curso de Letras - Licenciatura e Bacharelado Português-Italiano da Universidade Federal do Rio Grande do Sul é um dos poucos Cursos de Graduação em Língua Italiana no Brasil que oferece essas duas habilitações. Os dicionários são ferramentas

${ }^{1}$ A pesquisa e as reflexões que apresentamos aqui nasceram durante o percursoo que levou à tese de doutorado intitulada Bases teórico-metodológicas para um hiperdicionário semibilíngue de expressões idiomáticas italiano-português em meio a um AVA, defendida por Susana Termignoni em 2015 na Universidade Federal do Rio Grande do Sul, sob orientação de Maria José Bocorny Finatto. 
imprescindíveis para os estudantes das duas terminalidades, que precisam contar com bons instrumentos de apoio ao estudo do italiano.

No que tange à Fraseografia bilíngue, embora venha crescendo o interesse pelo ensino do italiano e as pesquisas em nível acadêmico estejam hoje em grande expansão, ainda há poucos dicionários fraseológicos bilíngues impressos ou eletrônicos no Brasil, sendo ainda mais escassos os materiais para o ensino de unidades fraseológicas (UFs), das quais as expressões idiomáticas (EIs) são uma subcategoria. Em pesquisas já realizadas, tentamos contribuir para minimizar essa lacuna no par de línguas italiano-português e enfatizar a importância do ensino dessas estruturas.

Procuramos, assim, estabelecer as bases teórico-metodológicas para o desenho e a implementação de um hiperdicionário semibilíngue italiano-português para compreensão de EIs, voltado a aprendizes brasileiros de língua italiana de nível intermediário-avançado, inserido em um Ambiente Virtual de Aprendizagem (AVA).

Não serão tratadas aqui as questões fraseográficas que se referem à construção do modelo de dicionário, mas sim as questões didáticas. Abordaremos o ponto de vista de estudiosos sobre o ensino de UFs e as razões pelas quais acreditamos que elas devam fazer parte do programa de aprendizagem de uma língua estrangeira, evidenciando a importância crescente e mundial que a Fraseodidática vem adquirindo.

\section{Fraseologia e Fraseodidática}

O termo fraseologia designa tanto o campo de investigação que tem como objeto de estudo e de pesquisa as unidades fraseológicas (a Fraseologia) quanto o variado conjunto composto por essas estruturas. Elas compreendem desde marcadores conversacionais ('Feliz Natal!'), colocações ('bala perdida'), expressões idiomáticas ('terminar em pizza'), até unidades mais fixas como os provérbios ('Devagar se vai ao longe'), as frases feitas ('Falando no diabo.... aparece o rabo') e os aforismos ('Diga ao povo que fico!').

Existem duas grandes tendências no âmbito da Fraseologia: a concepção estreita, que considera como UFs as combinações fixas de palavras que, por sua estrutura, se equivaleriam a um sintagma, e a concepção ampla, que considera como UFs as combinações fixas de palavras com estrutura sintagmática e com estrutura oracional (TRISTÁ PEREZ, 1998). Adotamos a concepção ampla de Fraseologia.

A Fraseodidática (ou didática da fraseologia) ocupa-se das questões relativas ao ensinoaprendizagem das UFs em língua materna (LM) ou em língua estrangeira (LE). Seu objetivo é permitir o reconhecimento, a aprendizagem e o emprego das unidades polilexicais com significado próprio e a aplicação adequada desse conhecimento à situação comunicativa (ETTINGER, 2008). 
Para González Rey (2010, p. 2, grifo nosso), “[...] essa disciplina define-se não somente pelo seu objeto de estudo, mas também pela função que reclama no seio da didática das línguas estrangeiras, uma vez que nesse âmbito a presença da fraseologia é quase inexistente". Sutkowska (2013) reforça essas palavras afirmando que a Fraseodidática é um campo de estudo "pouco e mal explorado" e que o próprio termo Fraseodidática não é conhecido pela maior parte dos estudiosos e professores de línguas, conhecendo-se menos ainda o que significa e qual seu campo de aplicação.

São muitos os pesquisadores que destacam a importância da fraseologia no âmbito do ensino e aprendizagem de LM e de LE para a obtenção de uma boa competência linguística. Para citar alguns, vale lembrar o pioneiro Bréal (1897), o próprio Bally (1951), González Rey (2002, 2006, 2010, 2014), Bárdosi (2010), Ettinger (2008) e Xatara (1998, 2001) para o francês; Tagnin $(1989,2005,2013)$ para o português brasileiro e o inglês; Penadés Martínez (1999), Ruiz (1997, 1998), Sevilla Muñoz y González Rodríguez (1984) para o espanhol, e Ortiz Álvarez $(2000,2011)$ para o espanhol e o português brasileiro como LE; Vale (2001), Fulgêncio (2008) e Fernandes (2011) para o português brasileiro; Zamora Muñoz $(1999,2005)$ e Navarro $(2005,2007)$ para o italiano e o espanhol; Zamora Muñoz et al. (2006) para o italiano, Bárdosi (2010) para o húngaro.

No entanto, o alcance dessa linha didática é ainda restrito devido à divergência de opiniões entre fraseófilos - para os quais a aquisição da fraseologia da LE é indispensável para uma boa competência comunicativa - e fraseófobos, que acreditam se tratar de uma parte totalmente supérflua do léxico (ETTINGER, 2008; GONZÁLEZ REY, 2010). É importante resumir aqui os argumentos que, para González Rey, estariam na base dessas duas posições. Antes disso, porém, é preciso esclarecer que essa autora refere-se às UFs com a denominação amplamente adotada na literatura francesa - expressions figées (expressões fixas/EFs). Conforme explicita, as EFs compreendem "as fórmulas de rotina ou expressões dialógicas, as expressões imagéticas (somatismos, cromatismos, zoomorfismos, expressões numerais, etc.), as colocações e as parêmias" (2010, p.3-4).

Para os fraseófobos, diz essa autora, a) um discurso pode ser construído sem que seja empregada uma só EF; b) as EFs pertencem ao domínio dos falantes nativos, e um aprendiz não precisa tornar-se um bilíngue para ser proficiente em LE; c) as EFs são mutáveis, e aprendê-las requer um grande investimento que nem sempre é compensador.

Por outro lado, González Rey pondera que os argumentos a favor do ensino da fraseologia de uma LE ultrapassam os inconvenientes. Portanto, para os fraseófilos, a) não dominar as EFs da LE denuncia a condição de aprendiz e desconhecê-las pode causar mal-entendidos e constrangimentos; b) embora o objetivo do aprendiz não seja falar como um nativo, ele almeja expressar-se de forma natural na LE, sobretudo depois de alguns anos de estudo; c) como a Linguística de Corpus revelou a imensa quantidade de EFs que permeiam uma língua, ficou demonstrado que elas são incontornáveis na didática das línguas; d) o ensino das EFs propicia 
uma abordagem cultural da língua a ser aprendida - uma expressão como 'Paris vale bem uma missa' realmente vale uma explicação!, exemplifica a fraseóloga, fazendo um jogo de palavras.

Não é demais enfatizar o quanto esse último argumento apontado por González Rey (2010) - o ensino das EFs propicia uma abordagem cultural da língua a ser aprendida - é importante quando a questão é defender a importância de ensinar EIs. De todos os argumentos apresentados, esse talvez seja o mais produtivo para a aquisição da competência em uma LE, pois compreender essa parcela do léxico pode descortinar múltiplos horizontes para quem está conhecendo um mundo novo e com ele quer interagir. Retomando o que diz González Rey (embora perdendo lamentavelmente o jogo de palavras, possível apenas com a expressão francesa), também acreditamos que as EIs italianas parlar male di Garibaldi e fare un quarantotto "valem bem uma explicação", contexto que ensejaria a oportunidade de abordar a história dos movimentos pela Unificação da Itália no século XIX.

Julgamos que aprender a identificar uma EI como uma unidade da LE que possui um significado específico, e compreender tal significado, é um ganho inquestionável para um estudante de LE. Saber usá-la na ocasião adequada denotaria um alto grau de proficiência nessa língua. Não por acaso, no Quadro Europeu Comum de Referência (QECR), as EIs estão situadas nos níveis mais altos da aprendizagem das línguas, principalmente pela dificuldade de compreensão que apresentam devido à sua opacidade.

\section{Por que ensinar expressões idiomáticas?}

Um falante, expressando-se em uma LE, pode produzir sentenças gramaticalmente corretas, embora nem sempre como aquelas produzidas por um nativo, ou seja, frequentemente ele constrói estruturas destoantes das usuais. Da mesma forma, pode não entender uma sequência de palavras, apesar de conhecê-las individualmente. Isso ocorre porque essas estruturas foram convencionadas. O uso de expressões fixas é um fato recorrente e constante na língua, por isso não se pode continuar a considerá-las como exceções e a pensar a língua exclusivamente como um conjunto de regras (FULGÊNCIO, 2008, p.28).

No ensino/aprendizagem de LE, essas estruturas convencionadas ainda não têm o reconhecimento que merecem como imensa parcela do léxico cujo legado histórico e social constitui valor inestimável para uma comunidade linguística. Com efeito, “[...] na práxis didática e nos textos, a reflexão sobre a linguagem figurada geralmente é negligenciada e o aprendizado das expressões idiomáticas é frequentemente relegado a atividades pouco significativas e marginais" (CARDONA, 2008, p.45).

Os estudos de fraseodidática demonstram que as UFs são um instrumento precioso no desenvolvimento da competência comunicativa dos aprendizes. Por essa razão, e dado o avanço alcançado nas pesquisas fraseológicas atuais, queremos reforçar os dois adjetivos utilizados 
por González Rey (2010) e por Sutkowska (2013), respectivamente, ao se referirem ao valor das UFs no domínio de uma LE: seu estudo é incontornável e seu papel na didática das LEs é incontestável.

Para refletirmos sobre a pertinência de ensinar UF, e em especial EIs, valemo-nos de uma pergunta de Ettinger: "Seriam os fraseologismos realmente tão importantes, representativos e imprescindíveis no uso da língua para serem ensinados e aprendidos na língua materna ou em uma língua estrangeira?" (2008, p.97).

Sobre a competência linguística dos falantes, Fulgêncio (2008, p.21) mostra que não só de regras e parâmetros é feito seu conhecimento e que o uso de agrupamentos memorizados é um dos processos envolvidos na construção de sentenças. Além de sequências mais frequentes, preferidas pelos falantes em situações pragmáticas definidas, existem sintagmas memorizados, fórmulas fixas, blocos de palavras que eles repetem como um todo coeso.

Estudos do Léxico-Gramática comprovaram empiricamente que as UFs são tanto ou mais numerosas que as construções livres (GROSS, 1994). De fato, elas permeiam completamente a nossa linguagem, embora nem sequer o percebamos. Pollio et al. (2000 apud CARDONA, 2008) analisaram, nos anos 1970, diferentes tipologias de texto em diversos contextos comunicativos, demonstrando que são produzidas em média 4/5 expressões figuradas em um minuto de conversa. Jackendoff estima que "[...] o número de expressões multipalavra no léxico de um falante é da mesma magnitude que o número de palavras isoladas" (1997, p.156).

Evidentemente há mais razões além do seu volume expressivo para se ensinar essas unidades: elas permeiam diferentes tipos de texto e de discurso, tanto na língua oral quanto na língua escrita. Em conversas cotidianas e em leituras de jornais e revistas, deparamo-nos com EIs pertencentes ao patrimônio linguístico universal - vittoria di Pirro/ lavarsi le mani -, que coexistem com EIs forjadas há bem menos tempo, em diferentes comunidades linguísticas - to rearrange the deck chairs on the Titanic/ ce n'est pas du caviarl 'não é nenhuma Brastemp'. As línguas possuem um background cultural em constante evolução - por isso, González Rey (2010) as classifica como 'mutáveis'-, e naturalmente vão incorporando novas unidades polilexicais que nascem de acontecimentos próprios da sua evolução histórica e cultural.

Observamos que as EIs, por exemplo, vão sendo utilizadas, sempre com maior frequência, até mesmo nos discursos especializados. Evidentemente de maneira esparsa e pontual, porém de qualquer forma surpreendente em se tratando de um terreno a princípio inóspito para o cultivo dessas unidades, que tradicionalmente (e erroneamente) eram consideradas típicas da coloquialidade. De fato, as EIs perpassam todo tipo de gênero textual. É assim que, na supervisão analítica com seus pares - todos especialistas, portanto -, o psicanalista relata que o paciente, querendo negar o problema, 'fez como a avestruz' ou 'fingiu-se de peixe morto'. Ou, em um artigo sobre um tema como metodologias do ensino de LE, Porcelli (1994) afirma que "[...] de nada adianta o professor ter muita bala na agulha, se não possui um alvo preciso". Como se vê "[...] existe um mecanismo de retomada de estruturas completas, recuperadas 
da memória como um conjunto coeso (FULGÊNCIO, 2008, p.20)", blocos de palavras préfabricados, memorizados e prontos para o uso que vêm em auxílio dos falantes nas interações comunicativas, até mesmo de cunho especializado entre pares. Parece-nos, portanto, ser inegável o papel de relevo que elas desempenham.

Já no jornalismo e na publicidade, as EIs são largamente empregadas, recurso valioso de jornalistas e publicitários para atrair a atenção do leitor em manchetes e chamadas publicitárias. Para dar um exemplo, uma expressão que nasceu no âmbito da propaganda brasileira é 'a família margarina', ou seja, a família perfeita, típica dos comerciais desse produto, que comumente utilizam a imagem de uma família sorridente, bonita e saudável. A língua italiana possui um correspondente na expressão la famiglia mulino bianco, na qual Mulino Bianco é o nome de uma famosa marca italiana de biscoitos e produtos de forno pertencente à tradicional indústria de massas Barilla, que veicula na mídia a mesma imagem familiar que transpira saúde e felicidade. Eis um caso em que a realidade é percebida de maneira muito semelhante por sistemas linguísticos diferentes.

Consequentemente, programas de estudo de LEs que não atentem para a importância dessas estruturas deixam em dificuldades o estudante que, inevitavelmente, sempre se defronta com elas quando em contato com a LE, em manchetes jornalísticas, em anúncios publicitários, em programas televisivos ou na própria interação oral cotidiana, não conseguindo, por vezes, captar nuances e referências importantes da realidade estrangeira.

A nosso ver, esse fato, por si só, já seria suficiente para justificar a importância de estudar essas unidades, se não para empregá-las, para compreendê-las. É o que afirma Ettinger (2008, p.100) ao defender que as UFs de uma LE devem ser aprendidas, em primeiro lugar, para adquirir uma competência fraseológica passiva. E conclui: "Contar com conhecimentos fraseológicos profundos em uma língua estrangeira facilita a compreensão leitora, dá pistas sobre as intenções do falante, torna as alusões contidas nos textos mais transparentes, permite entender jogos de palavras, sobretudo na publicidade etc." (IGLESIAS, 2007, p.70, apud ETTINGER, 2008, p.101, grifo nosso).

Essa visão é reforçada por Luque Nadal:

[...] se analisarmos artigos de opinião atuais em espanhol, inglês, francês, etc., vemos que eles frequentemente apresentam dificuldades de compreensão para um leitor não familiarizado com universos culturais específicos de um país e de uma época, o que implica que um estudante estrangeiro precisará conhecer não somente aspectos da gramática e do léxico de uma língua, mas também ter outros conhecimentos adicionais de tipo cultural. $(2009$, p.95)

Dignas de nota são também as palavras de Guilhermina Jorge: 
Introduzir a idiomaticidade no processo de aprendizagem de uma língua é oferecer aos aprendizes uma riqueza suplementar, um vínculo entre a língua e a experiência humana. Essa riqueza dá vida à língua e assim poderíamos falar de uma humanização da língua e do ensino (1992 apud GONZÁLEZ REY, 2010, p. 2-3).

Imagine-se, por exemplo, a dificuldade de um aprendiz brasileiro de língua italiana para entender a seguinte propaganda institucional em defesa de melhores condições de locomoção para os deficientes visuais:

Fig. 1: Jogo de palavras com a EI "mettere il bastone fra le ruote" em uma propaganda institucional

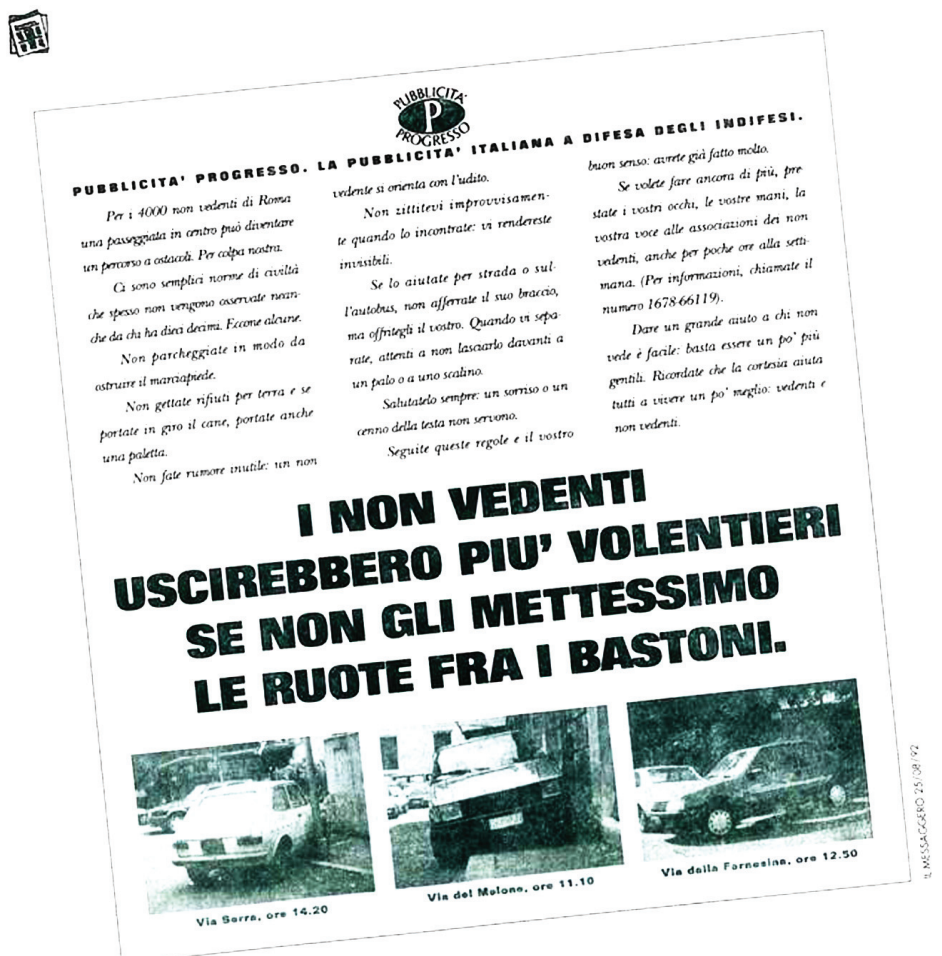

Fonte: Il Messaggero (1992) 
A EI italiana mettere un bastone fra le ruote (literalmente 'colocar um bastão entre as rodas') significa 'criar obstáculos ao andamento de uma atividade ou de um negócio' e equivale em português à EI 'jogar areia’ (TERMIGNONI, 2009, p.105). Nessa peça publicitária, há um jogo de palavras em que os vocábulos ruote (rodas) e bastoni (palavra que pode significar também 'bengalas') são invertidos, invertendo também a ideia de 'criar obstáculos', da expressão original: seriam as rodas dos carros, estacionados nas calçadas, a atrapalhar os deficientes visuais, cujos passos são orientados por suas bengalas. O artifício da deslexicalização, ou desautomatização (ZULUAGA, 1980) como é chamado, é muito usado para causar determinado efeito no leitor e chamar sua atenção, frequentemente em publicidade e na imprensa em geral.

Imagine-se, ainda, compreender as seguintes manchetes dos jornais italianos, em 2011, por ocasião dos festejos do $150^{\circ}$ aniversario da Unificação Italiana: $\grave{E}$ successo un quarantotto celebra l'Unità d'Italia / Viva l'Italia ma fateci parlare un po'male di Garibaldi / L'Italia è fatta facciamo i lettori / Viva Verdi! La colonna sonora del Risorgimento. Todos esses títulos contêm UFs subvertidas - EIs, aforismos, slogans - que fazem alusão a episódios da Unificação Italiana. Cristalizadas na língua e transmitidas de geração em geração, essas estruturas têm sua origem naquele período da história da Itália e são emblemáticas de eventos e personagens de relevo na cultura do país. Para quem estuda a língua italiana, o domínio dessas formas idiomáticas é de grande valia. Além de permitir decifrar manchetes desse tipo, oferece a oportunidade de ampliar o conhecimento da cultura e da história da Itália, pois a riqueza semântica que elas contêm é como um fio condutor que vai traçando esse percurso singular e irrepetível da história.

As EIs succedere (farelessere) un quarantotto permanecem ainda na fala cotidiana dos italianos, significando "uma situação imprevista de agitação e tumulto", reminiscência dos inúmeros movimentos revolucionários que sacudiram a Itália e a Europa da Restauração, sobretudo no ano de 1848, número que dá origem às EIs (quarantotto = 'quarenta e oito'). Também a EI parlar male di Garibaldi passou a fazer parte do idioma com o significado de "[...] falar mal de coisas consideradas intocáveis e indiscutíveis", uma referência ao papel desempenhado pelo herói de dois mundos no processo de Unificação Italiana.

Já o famoso aforismo Fatta l'Italia bisogna fare gli italiani, atribuído por alguns ao ministro Massimo D'Azeglio, e por outros a Camillo Benso, Conde de Cavour, indicava um dos problemas mais sérios que o governo precisou enfrentar depois da Unificação: as imensas diferenças entre o Norte e o Sul e a pouca unidade cultural e linguística da Itália recém-unificada. Por último, a popularidade do compositor vêneto Giuseppe Verdi originou o igualmente famoso acrônimo V.E.R.D.I. (Vittorio Emanuele Re D'Italia) presente no slogan VIVA VERDI!, o qual, escrito nos muros das cidades italianas sob o domínio austríaco, difundiu-se na península como forma de incitar a monarquia dos Savoia a tomar o poder, o que efetivamente se verificou em 1861. 
Aqui convém retomar o que diz Eugenio Coseriu (1980) sobre o discurso repetido ao incluir entre as diferentes categorias de UFs aquelas que podem ser "de citação", ou seja, partes de textos conhecidos (literários ou não) e importantes para se identificar as tradições linguísticas dos povos. Além das citadas, há também as que derivam de trechos literários, como, por exemplo, do Inferno da Divina Comédia, de Dante Alighieri (Lasciate ogni speranza voi che entratel senza infamia e senza lode), encontradas frequentemente em revistas e jornais da atualidade. Outro bom exemplo é o célebre aforismo Eppur si muove ..., que Galileu Galilei teria murmurado, cabeça baixa, diante do Tribunal da Santa Inquisição, logo após ter renegado sua crença de que a Terra se move ao redor do Sol, forma fixa que na Itália é repetida à exaustão, desautomatizada (Eppur si muore; Eppur si mangia, etc.) ou não (Eppur si muove), nas mais diversas circunstâncias comunicativas.

Fica claro, assim, que não se consegue decifrar uma infinidade de contextos se não se conhece esse tipo de estrutura na LE. A mesma fraseóloga Guilhermina Jorge, refletindo sobre as dificuldades que tem o aprendiz de LE de decodificar (e também de codificar) tais unidades, pondera:

O falante apercebe-se da existência da lexicalização e da originalidade semântica de dada estrutura na sua língua materna, mas terá mais dificuldades em reconhecê-la e interpretá-la na língua estrangeira. Deste modo, o falante enfrenta várias dificuldades no domínio da fraseologia: - dificuldades de reconhecimento (a EI pode confundir-se com frases não idiomáticas);

- dificuldades de interpretação (o sentido literal pode preceder o sentido idiomático e substituir esse);

- dificuldades de produção (o falante pode sentir dificuldade em reutilizar a expressão num contexto). (1997, p. 40, grifo nosso).

Além disso, importa ressaltar que, ao aprender essas construções, o aluno se integra mais à realidade da língua da qual está procurando se apropriar, e passa a entender que as diferenças existentes entre ela e sua língua não residem apenas nas formas linguísticas, mas expressam uma maneira diferente de se relacionar com o mundo.

\section{Conclusão}

Para além do domínio linguístico, conhecer as UFs e em especial as EIs de uma LE permite conhecer o povo e a cultura que lhes deu vida, o que descortina uma gama de possibilidades para o seu ensino, pela sua criatividade, expressividade e presença constante nos discursos cotidianos, podendo tornar-se um aprendizado muito atraente, inclusive em uma perspectiva 
contrastiva. Parece-nos evidente, assim, que a inserção dessas formas fixas e idiomáticas no processo de ensino/aprendizagem da língua italiana pode somente beneficiar nossos estudantes. Certamente, estudos sobre frequência e relevância das EIs contribuem para a seleção de quais delas incluir em cada nível de aprendizado.

Como acreditamos ter demonstrado, essas são possibilidades que deveriam ser exploradas nas aulas de italiano para brasileiros, tanto sob o aspecto linguístico-comunicativo quanto sob o aspecto histórico-cultural, com a apresentação de múltiplos e diferentes prismas da sociedade, da cultura e da história italianas, de forma original e, por que não, recreativa.

\section{Referências}

CARDONA, M. La comprensione e produzione de idioms: aspetti psicolinguistici e riflessioni glottodidattiche. Studi di Glottodidattica, Bari, Italia, n. 3, p. 45-64, 2008.

COSERIU, E. Lições de linguística geral. Rio de Janeiro, Ao Livro Técnico, 1980.

ETTINGER, S. Alcances e límites da fraseodidáctica. Dez preguntas clave sobre o estado actual da investigación. Cadernos de Fraseoloxía Galega, v. 10, p. 95-127, 2008.

FULGÊNCIO, L. Expressões fixas e idiomatismos do português brasileiro. 2008. 489 f. Tese (Doutorado em Letras) - Pontifícia Universidade Católica de Minas Gerais, Belo Horizonte, 2008. Disponível em: <http://www.biblioteca.pucminas.br/teses/Letras_FulgencioLM_1.pdf $>$. Acesso em: 15 de agosto de 2017.

GONZÁLEZ REY, M. I. La phraséodidactique en action: les expressions figées comme objet d'enseignement. La culture de l'autre: l'enseignement des langues à l'université, Actes. Lyon: [s. 1.], 2010 .

http://cle.ens-lyon.fr/espagnol/la-phraseodidactique-en-action-les-expressions-figees-commeobjet-d-enseignement-92012.kjsp. Acesso em: 15 de agosto de 2017.

GROSS, M. Constructing lexicon-grammars. In: Atkins, B.T.S.; Zampolli, A. (eds.) Computational approaches to the lexicon. Oxford, Oxford University Press, 1994. p. 213-263. . Méthodes en syntaxe: régime des constructions complétives. Paris, Hermann, 1975.

JACKENDOFF, R. The architecture of the language faculty. Cambridge, MIT Press, 1997.

JORGE, G. Reflexões em torno da tradutologia das construções fraseológicas na perspectiva interlínguas. Polifonia, Lisboa, n. 1, p. 33-43,1997.

LUQUE NADAL, L. Los culturemas: ¿unidades lingüísticas, ideológicas o culturales? Language Design, Barcelona, n. 11, p. 93-120, 2009.

SUTKOWSKA, M. De la phraseólogie à la phraseódidactique: études théoriques et pratiques. Katowice, Wydawnictwo Uniwersytetu Slaskiego, 2013.

TERMIGNONI, S. Bases teórico-metodológicas para um hiperdicionário semibilíngue de expressões idiomáticas italiano-português em meio a um ambiente virtual de aprendizagem. 2015. $426 \mathrm{f}$. Tese (Doutorado em Letras) - Universidade Federal do Rio Grande do Sul, Porto Alegre, 2015. Disponível em: <http://www.lume.ufrgs.br/handle/10183/130768>. Acesso em 08 de setembro de 2017. 
2009.

. Mil expressões idiomáticas e coloquialismos italiano-português. Porto Alegre, EDIPUCRS,

Parlar male di Garibaldi: modi di dire e detti dell’Unificazione Italiana.Comunità Italiana, Suplemento Mosaico, out. 2011.

ZINGARELLI, Nicola. Vocabolario della lingua italiana. Bologna, Zanichelli, 2008.

ZULUAGA, A. Introducción al estudio de las expresiones fijas. Tübingen, Max Hueber Verlag, 1980.

Recebido em 11/09/2017

Aprovado em 22/11/2017 